\title{
Sedentary Behavior Associates Young Adult Smoking Prevalence: Short Communication
}

\author{
Nawaf R Alshammari ${ }^{1}$, Jerome F Walker ${ }^{1}$
}

\begin{abstract}
Background Sedentary behavior and smoking prevalence in young adults, both prominent population health risks, are high value health promotion targets.

Methods Cross sectional design: Public-use data drawn from Wave 3 of the 2001-2002 National Longitudinal Study of Adolescent and Adult Health (Add Health), representing 18-26 year-old young adults, $n=4203$. This study examined the association of sedentary behavior and educational attainment with young adult smoking status (smoker versus nonsmoker), using logistic regression analysis. Sedentary behavior was approximated by self-reported hours spent weekly watching television. Follow-up analysis examined the association of nicotine dependence, measured by the Heaviness of Smoking Index (HSI), and sedentary behavior in young adult smokers, using General Linear Modeling.

Results Comparing sedentary behavior quartiles ( 1 and 4, least and most), smoking prevalence was $30 \%$ lower in quartile 1 $(O R=0.698[C l=0.566-0.862](p=0.001)$, and $19 \%$ lower in quartile $2(O R=0.813$ [Cl=0.662-0.998] ( $p=0.048)$. Young adult smoking prevalence was increased among young adults with high school education or less compared to those having attended at least some college (OR=2.22 [ $\mathrm{Cl}=1.876-2.635], \mathrm{p}=0.001)$. Follow-up General Linear Modeling showed no effect of sedentary behavior on the Heaviness of Smoking Index (HSI) among young adult smokers, $p=0.065$.

Conclusion Although sedentary behavior and lower educational attainment associate with greater young adult smoking prevalence, more sedentary young adult smokers are no more nicotine dependent. Potential benefits of incorporating measures to increased daily movement in into smoking cessation programs are discussed.

\section{About the AUTHORS}

1 Bellarmine University, Lansing School of Nursing and Health Sciences, Department of Respiratory Therapy, Louisville, KY, USA

Contact: Jerome Walker jwalker@bellarmine.edu

\section{Background}

Little research has examined the association between young adult smoking prevalence and sedentary behavior, although both are clearly related with poor long-term health outcomes $(1 ; 2)$. As of 2018, cigarette smoking in the US reached an encouraging all-time low (13.7\%), although an estimated 2000 adolescents still smoke their first cigarette each day (3) and the long-term effects of nicotine-related diseases are enormous. Annual U.S. mortality attributable to smoking approximates 500,000 deaths; morbidity affects another 16 million (4). At the same time, physical inactivity among young adults is alarming. According to Troiano et al (5), only $42 \%$ of US children ranging in age from 6 to 11 years meet the recommendation of least an one hour per day of physical activity, and only $8 \%$ of adolescents fulfill this aim. Preva- lence may even be as low as $<5 \%$ among young adults when physical activity is objectively measured via accelerometry.

Sedentary adolescents tend to be less physically active as young adults (6) and overall physical activity decreases with age (7). Furthermore, sedentary behavior in school-aged youth shows unwelcome outcomes on body mass index, academic accomplishment, and fitness level, underscoring the need for youth interventions to overcome future risks of sedentary behavior into adulthood (8). Smoking rates among young adults with high school education or less have been reported as greater than those with higher levels of education (9), and Green and others found that young adults who enrolled in college are likely less to smoke to those who do not (9). 
Regarding an association between smoking and inactivity, lower FEV1 has been reported among sedentary African Americans (10). Elsewhere, sedentary behavior was found to increase incidence of cancer up to $35 \%$ in smokers (11). Conversely, increased physical activity possibly reduces smoking cravings (12). Although baseline physical activity itself does not appear to predict adolescent smoking status 2-years after onset, an indirect effect of smoking-specific self-efficacy and physical activity may operate on quitting smoking (2). The research findings are mixed, however, with others finding no direct effect of activity level on smoking (13;14).

This study was conducted first to determine if sedentary behavior associates with smoking prevalence in a nationally representative sample of young adults. Second was to determine if there is an association between physical inactivity and nicotine dependence in young adult smokers. Potential interventions pointed toward sedentary behavior in smokers, particularly young adults prior to developing overt disease, may better inform health promotion programs (15).

\section{Methods}

\section{Design}

National Longitudinal Study of Adolescent and Adult Health (Add Health) public-use data were examined, using a cross-sectional design comprised of 18-26 yearold young adults surveyed during 2001-2002 in Wave 3. At this time Add Health houses 5 waves of population level information about family, relationships, sexual experiences, childbearing, educational histories, labor force involvement, civic participation, religion and spirituality, mental health, health insurance, illness, delinquency and violence, gambling, substance abuse, and involvement with criminal justice system.

Add Health data are deposited at the Carolina Population Center and were collected after informed consent for participation from each participant in accordance with University of North Carolina School of Public Health institutional review board (IRB) guidelines. This protocol involved secondary analysis of portions of the public-use Add Health data set and underwent exempt review by the Bellarmine University IRB (IRB\#828).

\section{Young Adult Smoking Status}

The dependent variable in the study is bivariate young adult smoking status (smoker or nonsmoker) determined by the Wave 3 In-Home Interview question: "During the past 30 days, on how many days did you smoke cigarettes?" Wave 3 respondents reporting having smoked between 1 and 30 days within the past month were classified as smokers.

\section{Sedentary Behavior}

A marker of sedentary behavior and study independent variable is the Wave 3 Add Health survey question: 'On the average, how many hours a week do you spend watching television?' For purposes of analysis, the variable was coded into quartiles, $1-4$, in a less to more scale. Table 1 displays the range of TV viewing (hrs/week) across these respective quartiles.

\section{Education Level}

Education level was introduced into the model as a second independent variable. Respondents' Wave 3 level of education coded o for high school or less and 1 for some college or more.

\section{Heavy of Smoking Index}

In follow-up analysis, Wave 3 Add Health survey questions making up the Heavy of Smoking Index (HSI), the Fagerstrom Test for Nicotine Dependence short form, were coded and summed to produce a o-6, less to more, to measure nicotine dependence (16). The two HSI survey items are: 'On the days that you smoke, how soon after you wake up do you have your first cigarette?': within 5 minutes (3 points), 6-30 minutes ( 2 points), 31-6o minutes ( 1 point), after 60 minutes (o points); and 'How many cigarettes do you typically smoke per day?': 10 or fewer (o points), 11-20 (1 point), 21-30 (2 points), 31 or more (3 points). HSI scores classify as: 0-2 low dependence, 3-4 moderate dependence, and 5-6 high dependence.

\section{Data Analysis}

Logistic regression was applied to evaluate bivariate Wave 3 Young Adult Smoking Status (yes or no) as predicted by categorical Sedentary Behavior (hours per week spent watching TV in quartiles), and level of education (high school or less versus some college or more), following complex sample survey procedures in SPSS (version 26, SPSS Inc, Chicago, IL). Follow-up analysis using General Linear Modeling procedures in SPSS 26 examined young adult nicotine dependence as measured by the Heaviness of Smoking Index and its possible association with the main study questions.

\section{Results}

The study sample was comprised of 4203 of 4882 (86\%) young adults surveyed in Wave 3 of Add Health that provided responses to each study variable of interest. Mean (SD) age of the sample was 21.96 (1.78) years. The sedentary behavior and education characteristics of the sample appear in Table 1. 
Table 1. Study Independent variable proportions, Add Health Wave $3^{\mathrm{a}}$

\begin{tabular}{ccc}
\hline Sedentary Behavior Quartiles & Number & Percent \\
1 (0-4 TV hrs/wk) & 1068 & $25.4 \%$ \\
2 (5-10 TV hrs/wk) & 1425 & $33.6 \%$ \\
3 (11-19 TV hrs/wk) & 1021 & $23.7 \%$ \\
4 ( $\geq 20$ TV hrs/wk) & 689 & $17.3 \%$ \\
Education Level & & \\
High school & 1950 & $46.4 \%$ \\
Some college or more & 2253 & $53.6 \%$ \\
\hline
\end{tabular}

a Values are unweighted

23.6\% of these young adults smoked within the past 30 days, averaging nearly 1 pack/day cigarette use [Mean (SE) 16.39 (11.55) cigarettes/day], with moderate level nicotine dependence: mean (95\% CI) Heaviness of Smoking Index $(\mathrm{HSI})=2.74(2.64-2.85)$. Over twothirds $(67.4 \%)$ of the sample reported at least 6 years smoking duration based on Wave 1 of Add Health inhome interview responses. The overall model showed both Sedentary Behavior and Education Level significantly associated with young adult smoking status (Table 2).

\begin{tabular}{lrc} 
Table 2. Tests of Model Effects & & \\
\hline Source & Wald F & Significance \\
\hline (Corrected Model) & 26.114 & $<0.001$ \\
(Intercept) & 102.102 & $<0.001$ \\
Sedentary Behavior & 5.072 & $<0.002$ \\
Education Level & 86.461 & $<0.001$ \\
\hline
\end{tabular}

Comparing smoking prevalence and sedentary behavior quartiles [ 1 to 4 , least to most], the least and second least sedentary quartiles, respectively, were 30\% $(\mathrm{p}=0.001)$ and 19\% $(\mathrm{p}=0.048)$ less likely to smoke (Table 3). Comparing young adults with high school education or less to those with some college or more, the former were 2.22 times more likely to smoke.

Table 3. Parameter estimates of sedentary behavior and education effects on young adult smoking status ${ }^{€}$

\begin{tabular}{ccr}
\hline & $\begin{array}{r}\text { Odds Ratio (OR) of } \\
\text { Adult Smoking }\end{array}$ & $\begin{array}{r}95 \% \text { Confidence } \\
\text { Interval }\end{array}$ \\
\hline $\begin{array}{c}\text { Sedentary Behavior } \\
\text { Quartile 1 v } 4\end{array}$ & $0.698(p=0.001)$ & $0.566-0.862$ \\
Quartile 2 v 4 & $0.813(p=0.048)$ & $0.662-0.998$ \\
Education Level & & \\
Less v. more & $2.223(p=0.000)$ & $1.876-2.635$ \\
\hline
\end{tabular}

${ }^{€}$ Referents were Sedentary Behavior Quartile 4 (most) and Less Education Level.
Follow-up General Linear Modeling of smokers in the sample showed no effect of sedentary behavior on the Heaviness of Smoking Index (HSI), p=0.065. However, those with high school education or less showed significantly greater HSI compared to those with more education (Mean (SE) 2.39 (o.065) versus 1.54 (o.080), $\mathrm{p}=0.001)$.

\section{Discussion}

In this study, increased sedentary behavior (approximated by self-reported hours/week watching TV) was found to be associated with increased smoking prevalence in a nationally representative sample of 18-26 year-old young adults. Another study finding showed an indirect relationship between smoking and level of education was observed. Others have reached similar conclusions (17-21).

Cigarette smoking classifies as a youth-onset disorder characterized by nondaily initial use $(22 ; 23)$. However, nicotine is highly addictive (24) and withdrawal symptoms, including irritability, restlessness and cravings, emerge after minimal use (25). Measurable nicotine dependence develops in nearly $20 \%$ of adolescent smokers by 14-15 years of age (26). Correspondingly, the majority of young adults surveyed in Wave 3 of Add Health in this study started smoking at least 6 years earlier as adolescents and were moderately nicotine dependent.

Adolescent smokers are less likely to meet recommended physical activity guidelines than nonsmokers $(27 ; 28)$. In addition, sedentary behavior correlates with poor perceived health-related quality of life (29). Arguably, young adults are a particularly important target for smoking cessation interventions. Smoking duration more strongly associates with COPD and lung cancer than smoking intensity, e.g., cigarettes smoked per day (30;31). Quitting before age 35 produces life expectancy comparable to never smokers, beyond which time adverse health effects are increasingly irreversible (32-34).

There is little evidence reducing sedentary behavior or increasing physical activity directly influence smoking cessation (35). Increased activity does, however, associate with greater self-efficacy, and self-efficacy with quitting (36). Therefore, self-efficacy influenced by activity may mediate quitting smoking in adolescents and young adults. In this study, more sedentary young adult smokers are no more nicotine dependent. Nicotine dependence and inactivity appear to operate independently, in agreement with our previous work 
(37). In terms of promoting less sedentary behavior, more dependent young adult smokers are at no disadvantage. To the degree physical activity promotes more healthful behaviors in other areas, it holds promise to mitigate smoking (38). In this regard, the transtheoretical model (TTM) may inform an approach that promotes PA in young adult smokers in the precontemplation stage of quitting. While this study's cross-sectional design prevents determining causal effects, improved quality of life and self-efficacy associated with even modest PA improvement may encourage smokers to enter the contemplative stage of quitting.

In conclusion, promoting even modest levels of increased daily movement as a supplement to other behavioral and pharmacotherapy-based approaches to smoking cessation may indirectly improve readiness to quit. A strength of this study includes its use of a nationally representative sample of US smokers. Limitations include the cross-sectional design, preventing any cause and effect conclusion to render causation. Prospective or experimental studies are needed utilizing objective measures of sedentary behavior. Further, self-reported studies are limited in that smokers may not be able to provide accurate descriptions of their behavior and may have bias. Smoking status was evaluated based on self-reported monthly cigarette use. Lastly, sedentary behavior and physical activity may operate independently on various outcomes and physical activity was not covaried out in the model.

\section{Acknowledgements}

This research uses data from Add Health, a program project directed by Kathleen Mullan Harris and designed by J. Richard Udry, Peter S. Bearman, and Kathleen Mullan Harris at the University of North Carolina at Chapel Hill, and funded by grant Po1-HD31921 from the Eunice Kennedy Shriver National Institute of Child Health and Human Development, with cooperative funding from 23 other federal agencies and foundations. Information on how to obtain the Add Health data files is available on the Add Health website (http:// www.cpc.unc.edu/addhealth). No direct support was received from grant P01-HD31921 for this analysis.

Contributors: Conception and design: NRA, JFW. Analysis and interpretation of data: NRA, JFW. Drafting, revising and final approving of the article: NA, JFW.

Competing interests: None declared.

Funding: None declared.

Patient content: Not required.

Ethics approval: Add Health data are deposited at the University of North Carolina Population Health Center. Data were obtained under participant protection guidelines of the University of North Carolina School of Public Health institutional review board (IRB).

\section{References}

(1) Brummett BH, Babyak MA, Siegler IC, Mark DB, Williams RB, Barefoot JC. Effect of Smoking and Sedentary Behavior on the Association between Depressive Symptoms and Mortality from Coronary Heart Disease. Am J Cardiol. 2003;92:529-532. doi: 10.1016/S0002-9149(03)00719-7.

(2) Loprinzi PD, Walker JF. Nicotine Dependence, Physical Activity, and Sedentary Behavior among Adult Smokers. N Am J Med Sci. 2015;7(3):94-9. doi: 10.4103/1947-2714.153920.

(3) Creamer MR, Wang TW, Babb S, et al. Tobacco Product Use and Cessation Indicators Among Adults - United States, 2018. MMWR Morb Mortal Wkly Rep. 2019;68:1013-1019. doi: 10.15585/mmwr.mm6845a2.

(4) U.S. Department of Health and Human Services. The Health Consequences of Smoking: 50 Years of Progress. A Report of the Surgeon General. Atlanta, GA: U.S. Department of Health and Human Services, Centers for Disease Control and Prevention, National Center for Chronic Disease Prevention and Health Promotion, Office on Smoking and Health, 2014.

(5) Troiano RP, Berrigan D, Dodd KW, Masse LC, Tilert T, McDowell M. Physical Activity in the United States Measured by Accelerometer. Med Sci Sports Exerc. 2008;40:181-8. doi: 10.1249/mss.0b013e31815a51b3.

(6) Gordon-Larsen P, Nelson MC, Popkin BM. Longitudinal Physical Activity and Sedentary Behavior Trends: Adolescence to Adulthood. Am J Prev Med. 2004;27:277-283. doi: 10.1016/j.amepre.2004.07.006.

(7) Sallis JF. Age-Related Decline in Physical Activity: a Synthesis of Human and Animal Studies. Med Sci Sports Exerc. 2000;32:1598-600. doi: 10.1097/00005768-200009000-00012.

(8) Tremblay MS, LeBlanc AG, Kho ME, et al. Systematic Review of Sedentary Behaviour and Health Indicators in School-Aged Children and Youth. Int J Behav Nutr Phys Act. 2011;8:98-98. doi: 10.1186/1479-5868-8-98.

(9) Solberg LI, Asche SE, Boyle R, McCarty MC, Thoele MJ. Smoking and Cessation Behaviors among Young Adults of Various Educational Backgrounds. Am J Public Health. 2007;97:1421-1426. doi: 10.2105/AJPH.2006.098491. (10) Jenkins BWC, Sarpong DF, Addison C, et al. Joint Effects of Smoking and Sedentary Lifestyle on Lung Function in African Americans: the Jackson Heart Study Cohort. Int J Environ Res Public Health. 2014;11:1500-1519. doi: 10.3390/ijerph110201500.

(11) Colditz GA, Wei EK. Preventability of Cancer: the Relative Contributions of Biologic and Social and Physical Environmental Determinants of Cancer Mortality. Annu Rev Public Health. 2012;33:137-56. doi: 10.1146/ annurev-publhealth-031811-124627.

(12) Roberts V, Maddison R, Simpson C, Bullen C, Prapavessis H. The Acute Effects of Exercise on Cigarette Cravings, Withdrawal Symptoms, Affect, and Smoking Behaviour: Systematic Review Update and Meta-Analysis. Psychopharmacology (Berl). 2012;222:1-15. doi: 10.1007/s00213-012-2731-z. (13) Kaczynski AT, Manske SR, Mannell RC, Grewal K. Smoking and Physical Activity: A Systematic Review. Am J Health Behav. 2008;32(1):93-110. doi: 10.5555/ajhb.2008.32.1.93.

(14) Ussher MH, Taylor AH, Faulkner GE. Exercise Interventions for Smoking Cessation. Cochrane Database Syst Rev. 2014;8:Cd002295. doi: 10.1002/14651858.CD002295.pub5.

(15) Brisson C, Larocque B, Moisan J, Vezina M, Dagenais GR. Psychosocial Factors at Work, Smoking, Sedentary Behavior, and Body Mass Index: A Prevalence Study among 6995 White Collar Workers. J Occup Environ Med. 2000;42:40-6. doi: 10.1097/00043764-200001000-00011.

(16) Fagerstrom KO, Heatherton TF, Kozlowski LT. Nicotine addiction and its assessment. Ear Nose Throat J. 1990;69:763-5.

(17) Giannakopoulos G, Panagiotakos D, Mihas C, Tountas Y. Adolescent Smoking and Health-Related Behaviours: Interrelations in a Greek School-Based Sample. Child Care Health Dev. 2009;35:164-70. doi: 10.1111/i.1365-2214.2008.00906.x.

(18) Strine TW, Okoro CA, Chapman DP, et al. Health-Related Quality of Life and Health Risk Behaviors among Smokers. Am J Prev Med. 2005;28:182-7. doi: 10.1016/i.amepre.2004.10.002.

(19) Wilson DB, Smith BN, Speizer IS, et al. Differences in Food Intake and Exercise by Smoking Status in Adolescents. Prev Med. 2005;40:872-9. doi: 10.1016/i.ypmed.2004.10.005.

(20) Paavola M, Vartiainen E, Haukkala A. Smoking, Alcohol Use, and Physical Activity: A 13-Year Longitudinal Study Ranging from Adolescence 


\section{Research and Best Practice}

into Adulthood. J Adolesc Health. 2004;35:238-44. doi: 10.1016/i.jadohealth.2003.12.004.

(21) Breslau N, Peterson EL. Smoking Cessation in Young Adults: Age at Initiation of Cigarette Smoking and other Suspected Influences. Am J Public Health. 1996;86:214-220.

(22) Lee J, Halpern-Felsher BL. What Does it Take To Be a Smoker? Adolescents' Characterization of Different Smoker Types. Nicotine Tob Res. 2011;13:1106-13. doi: 10.1093/ntr/ntr169.

(23) Pomerleau OF, Collins AC, Shiffman S, Pomerleau CS. Why Some People Smoke and Others Do Not: New Perspectives. J Consult Clin Psychol. 1993;61:723-731.

(24) Benowitz NL. Nicotine Addiction. N Engl J Med. 2010;362:2295-303. doi: 10.1056/NEJMra0809890.

(25) Difranza JR, Savageau JA, Rigotti NA, et al. Development of Symptoms of Tobacco Dependence in Youths: 30 Month Follow Up Data from the DANDY Study. Tob Control. 2002;11:228-235. doi: 10.1136/tc.11.3.228.

(26) Dierker L, Swendsen J, Rose J, He J, Merikangas K. Transitions to Regular Smoking and Nicotine Dependence in the Adolescent National Comorbidity Survey (NCS-A). Ann Behav Med. 2012;43:394-401. doi: 10.1007/ s12160-011-9330-9.

(27) Larson NI, Story M, Perry CL, Neumark-Sztainer D, Hannan PJ. Are Diet and Physical Activity Patterns Rrelated to Cigarette Smoking in Adolescents? Findings from Project EAT. Prev Chronic Dis. 2007;4(3):A51-A51.

(28) MacArthur G, Caldwell DM, Redmore J, et al. Individual-, Family-, and School-Level Interventions Targeting Multiple Risk Behaviours in Young People. Cochrane Database Syst Rev. 2018;10:Cd009927. doi: 10.1002/14651858.CD009927.pub2.

(29) Gopinath B, Hardy LL, Baur LA, Burlutsky G, Mitchell P. Physical Activity and Sedentary Behaviors and Health-Related Quality of Life in Adolescents.
Pediatrics. 2012;130:e167-74. doi: 10.1542/peds.2011-3637.

(30) Bhatt SP, Kim YI, Harrington KF, et al. Smoking Duration Alone Provides Stronger Risk Estimates of Chronic Obstructive Pulmonary Disease than Pack-Years. Thorax. 2018;73:414-421. doi: 10.1136/thoraxinl-2017-210722. (31) Flanders WD, Lally CA, Zhu BP, Henley SJ, Thun MJ. Lung Cancer Mortality in Relation to Age, Duration of Smoking, and Daily Cigarette Consumption: Results from Cancer Prevention Study II. Cancer Res. 2003;63:6556-62. (32) Lee CW, Kahende J. Factors Associated with Successful Smoking Cessation in the United States, 2000. Am J Public Health. 2007;97:1503-9. doi: 10.2105/aiph.2005.083527.

(33) Doll R, Peto R, Boreham J, Sutherland I. Mortality in Relation to Smoking: 50 Years' Observations on Male British Doctors. BMJ. 2004;328:1519. doi: 10.1136/bmj.38142.554479.AE.

(34) Husten CG. Smoking Cessation in Young Adults. Am J Public Health. 2007;97:1354-6. doi: 10.2105/ajph.2007.117358.

(35) Frith E, Loprinzi PD. Exercise Facilitates Smoking Cessation Indirectly via Intention to Quit Smoking: Prospective Cohort Study Among a National Sample of Young Smokers. Am J Health Promot. 2018;32:1234-1238. doi: $10.1177 / 0890117117717372$.

(36) Nduaguba SO, Ford KH, Rascati K. The Role of Physical Activity in the Association Between Smoking Status and Quality of Life. Nicotine Tob Res. 2019;21:1065-1071. doi: 10.1093/ntr/nty052.

(37) Loprinzi PD, Walker JF. Nicotine Dependence, Physical Activity, and Sedentary Behavior among Adult Smokers. N Am J Med Sci. 2015;7:94-9. doi: 10.4103/1947-2714.153920.

(38) Bloom EL, Minami H, Brown RA, Strong DR, Riebe D, Abrantes AM. Quality of Life after Quitting Smoking and Initiating Aerobic Exercise. Psychology, Health \& Medicine. 2017;22:1127-1135. doi: $\underline{10.1080 / 13548506.2017 .1282159 .}$. 